\title{
Arteriovenous Malformation of the Cervical Cord Region
}

\author{
Keizo Tanitame
}

Key words: intramedullary arteriovenous malformation, perimedullary arteriovenous fistula, cervical cord, conservative management

(Intern Med 59: 3111, 2020)

(DOI: 10.2169/internalmedicine.5273-20)
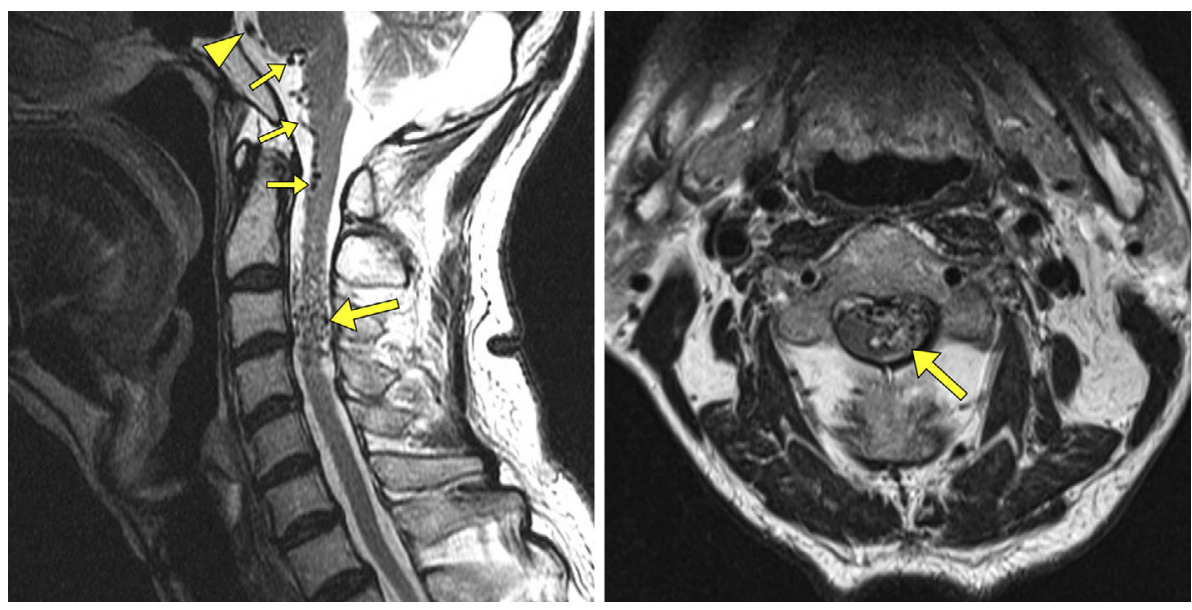

Picture.

A 58-year-old man presented to the neurology department with mild weakness of the left upper and lower extremities. A physical examination revealed no abnormal findings except for a left Babinski reflex. T2-weighted magnetic resonance imaging (MRI) (Picture) revealed intramedullary and perimedullary serpiginous structures with flow voids at C3-4 (large arrows) that were connected to the right vertebral artery (VA) at the pontine level (arrowhead). He was diagnosed with a combination of intramedullary arteriovenous malformation (AVM) and perimedullary arteriovenous fistula (AVF) of cervical cord, the main feeding artery (small arrows) of which arises from the right intracranial VA (arrowhead). Intramedullary AVMs typically occur at the cervicothoracic level, whereas dural and perimedullary AVFs predominantly occur at the thoracolumbar level. The patient's symptoms were stable, and he had no history of subarachnoid or intramedullary hemorrhaging. Although several treatment options, including endovascular embolization (1), stereotactic radiotherapy (2), open surgery, and their combi- nations, were discussed, conservative management was ultimately selected. During eight years' follow-up, there were no symptomatic or MRI changes.

The author states that he has no Conflict of Interest (COI).

\section{References}

1. Endo T, Endo H, Sato K, Matsumoto Y, Tominaga T. Surgical and endovascular treatment for spinal arteriovenous malformations. Neurol Med Chir (Tokyo) 56: 457-464, 2016.

2. Kalani MA, Choudhri O, Gibbs IC, et al. Stereotactic radiosurgery for intramedullary spinal arteriovenous malformations. J Clin Neurosci 29: 162-167, 2016.

The Internal Medicine is an Open Access journal distributed under the Creative Commons Attribution-NonCommercial-NoDerivatives 4.0 International License. To view the details of this license, please visit (https://creativecommons.org/licenses/ by-nc-nd/4.0/).

Department of Diagnostic Radiology, Hiroshima Prefectural Hospital, Japan

Received: May 7, 2020; Accepted: May 27, 2020; Advance Publication by J-STAGE: July 28, 2020

Correspondence to Dr. Keizo Tanitame, tntrad@gmail.com

(C) 2020 The Japanese Society of Internal Medicine. Intern Med 59: 3111, 2020 